\title{
A qualitative evaluation of home-based contraceptive and sexual health care for teenage mothers
}

\author{
Mark Hayter ${ }^{1}$, Catriona Jones ${ }^{2}$, Jenny Owen ${ }^{3}$ and Christina Harrison ${ }^{4}$ \\ ${ }^{1}$ Professor of Sexual and Reproductive Health, Faculty of Health and Social Care, University of Hull, Hull, UK \\ ${ }^{2}$ Senior Research Fellow, Faculty of Health and Social Care, University of Hull, Hull, UK \\ ${ }^{3}$ Honorary Senior Lecturer in Social Science and Health, ScHARR, University of Sheffield, UK \\ ${ }^{4}$ Assistant Director for Children, Young People \& Families, Rotherham Doncaster and South Humber NHS Foundation \\ Trust, UK
}

\begin{abstract}
Aim: This paper reports on the findings from a qualitative study exploring the experiences of teenage mothers using a nurse-led, home-based contraceptive service designed to prevent repeat unplanned pregnancies. The aim was to understand if, and how the service was effective in equipping teenage mothers to make informed choices about contraception, thus preventing a second pregnancy. Background: Unplanned teenage pregnancy remains a significant focus of health and social policy in the United Kingdom (UK). Despite the long-term pattern of declining conception rates, the UK continues to report higher rates than comparable countries elsewhere in Europe. Current estimates suggest that approximately one fifth of births amongst under 18 's are repeat pregnancies (Teenage Pregnancy Independent Advisory Group, 2009). Services that are designed to reduce second unplanned pregnancies are an important element in promoting teenage sexual health. However, there has been no UK research that explores this kind of service and the experiences of service users. Methods: We conducted a qualitative interview study. From 2013-2014 we interviewed 40 teenage mothers who had engaged with the nurse-led, home-based contraceptive service. Findings: The data demonstrates that the service was effective in preventing repeat pregnancies in a number of cases. Among the aspects of the service which were found to contribute to its effectiveness were privacy, convenience, flexibility, appropriately timed access, the non-judgemental attitude of staff and ongoing support.
\end{abstract}

Key words: childbearing; contraception; pregnancy; sexual health; teenagers

Received 23 February 2015; revised 3 July 2015; accepted 26 July 2015; first published online 28 September 2015

\section{Introduction}

Reports from the Office for National Statistics continue to demonstrate a long-term decline in the rate of teenage pregnancy in England and Wales (Office for National Statistics, 2015). The latest available figures, for 2013 , show that $<25$ young women (aged under 18) in every 1000 became

Correspondence to: Catriona Jones, Faculty of Health and Social Care, University of Hull, Dearne Building, Room 113, Cottingham Road, Hull, HU6 7RX, UK. Email: C.Jones@ hull.ac.uk pregnant in that year: the lowest under-18 conception rate since 1969. At the same time, there is continuing concern about the social, emotional and economic challenges faced by teenage parents. Much debate has focused on the argument that pre-pregnancy levels of deprivation are more important than chronological age, in contributing to these challenges (Arai, 2009). But alongside this fundamental debate, there has been a continuing policy impetus to continue reducing teenage conceptions and births, and to minimise the likelihood of second and subsequent unplanned pregnancies among young parents. Current 
estimates suggest that approximately one-fifth of births among under $18 \mathrm{~s}$ are repeat pregnancies (Teenage Pregnancy Independent Advisory Group, 2009). As such, services that are designed to reduce second unplanned pregnancies are an important element in promoting teenage sexual health. However, there has been no UK research that explores this kind of service and the experiences of service users. This paper reports the findings from interviews with service users as part of a larger study evaluating the whole service.

\section{Background}

Unplanned teenage pregnancy remains a significant focus of health and social policy in the United Kingdom. Despite the long-term pattern of declining conception rates noted above, the United Kingdom continues to report higher rates than comparable countries elsewhere in Europe (Office for National Statistics, 2015). In addition, scrutiny of UK abortion rates reveals an increase in abortions of repeat pregnancy in women under the age of 19 (Collier, 2009). There is also evidence that one teenage unplanned pregnancy is predictive of a repeat unplanned conception, as the sexual risk factors continue after birth. These include inconsistent contraception use, social isolation, poor self-efficacy and lack of sexual health service access (Birch, 1997). Teenage conception can have a negative, long-term social and economic impact upon the mother (Rigsby et al., 1998; Klerman, 2004; Wellings, 2007), and also negative effects upon the child (Nanchahal et al., 2005), including poorer physical and mental health outcomes (Furstenberg et al., 1987; Corbin, 2004).

There is evidence to suggest that an unplanned repeat pregnancy compounds these problems significantly (Rowlands, 2010). Preventing repeat teenage pregnancy is therefore an important strand of sexual health promotion. The research evidence on the prevention of repeat teenage pregnancy is limited but shows that a number of factors influence the effectiveness of health care services aimed at reduction in adolescents. One factor that has been seen as influencing effectiveness is the delivery of sexual health services in the new mother's own home setting, including the opportunity to discuss contraceptive intentions and sexual health and to access practical advice (Meade and Ickovics, 2005; Black et al., 2006). This literature has some key limitations, as it is almost exclusively drawn from US studies and these studies exclusively employ quantitative methods to measure multifaceted interventions. This makes it difficult or impossible to evaluate the specific impact of home care by sexual health professionals. So, although there are some studies that suggest that nurse-led outreach services may be effective, there is no evidence of how they are received and experienced by the young women themselves. In other areas of sexual health for young people, the experiences of patients have been vital in developing a better understanding of the patient experience and subsequent delivery of care - for example, school-based sexual health care (Owen et al., 2010). Addressing the gap in our knowledge base in relation to outreach services to prevent repeat pregnancies will enable the experiences of young women to inform the future of this important area of National Health Service patient care. The evidence base for how young mothers experience this type of care is lacking.

\section{Setting}

The study took place in a town in the North of England. The setting was within the Young Person's Sexual Health Service, which is responsible for the delivery of home-based contraceptive and sexual health advice and treatment to 16-19-yearold new mothers. The service is called Preventing Second Pregnancy (P2P) and provides home visits to $\sim 200$ teenage mothers a year. New mothers are informed about the service by the Community Midwife and, if willing, are referred to the P2P team. Information on methods of contraception and safer sex are given to women in the first few weeks after childbirth. Women are counselled and helped towards making decisions about their future contraception and sexual health needs. The P2P staff encourage women to attend a sexual health or GP surgery clinic for follow up contraception after the P2P visit, however, all new mothers seen by P2P staff have access to P2P contact numbers so they can make contact for advice if needed. Once P2P involvement ceases, the staff rely on referral from health visitors if further P2P involvement is required. 
Table 1 Demographics of the research participants

\begin{tabular}{|c|c|c|c|c|c|c|c|c|c|c|c|}
\hline & \multicolumn{5}{|c|}{$\begin{array}{c}\text { Age (at time of } \\
\text { interview) }\end{array}$} & \multicolumn{4}{|c|}{ Living arrangements } & \multicolumn{2}{|c|}{ Partner employment } \\
\hline & 17 & 18 & 19 & 20 & 21 & With partner & With family & Alone & Family + partner & Employed & Un-employed \\
\hline $\begin{array}{l}\text { Teenage } \\
\text { mothers using } \\
\text { the service in } \\
\text { the last two } \\
\text { years }(n=40)\end{array}$ & 6 & 8 & 16 & 6 & 4 & 20 & 9 & 3 & 8 & 18 & 22 \\
\hline
\end{tabular}

\section{Method}

\section{Sample}

In keeping with a qualitative approach, sampling used a purposive approach designed to recruit participants best suited to provide meaningful data. Sampling ensured the selection of participants from each of the following.

New female patients aged 16-19 years using the nurse-led, home-based sexual health care service for the first time.

Female patients who had used the service in the last two years (when aged 16-19 years).

The participants were recruited through the nurse-led, home-based sexual health care service. New and previous users of the service were informed about the research from the nurse delivering the service between April 2013 and July 2014 and provided with a patient information sheet. After a week, if agreeable to participating in the study, an appointment was made for the interview to take place. The interview was conducted by a researcher in the mother's home. The demographics of the research participants are available in Table 1.

\section{Ethics}

NHS ethics and research governance approval was sought and obtained prior to commencement of the project. Full informed, written consent was obtained after participants had the chance to read the information sheet about the study. The voluntary nature of participation was emphasised and the right to withdraw from the study highlighted. Assurances of confidentiality were given.

\section{Data collection}

Data were collected by in-depth, semi-structured interviews conducted in the participant's home.
Interviews were conducted in private and were recorded digitally. Interviews were guided by an interview schedule of open questions and prompts developed in partnership with patient representatives on the project advisory group. The schedule was intended as a flexible guide for the interviewer and was used to ensure the common broad issues were covered with all participants, however, the interviewer was experienced and able to divert from the schedule as and when necessary during the interview.

\section{Data analysis}

Data were analysed using the Framework Analysis Approach (Ritchie and Spencer, 1994), which is argued to be the most appropriate analytical approach to employ in this study. This method is becoming an increasingly popular approach to the management and analysis of qualitative data in health research (Gale et al., 2013). It is designed to provide a clear series of analytical steps and is suited to the management of large amounts of qualitative data (Murtagh et al., 2006). The Framework Approach has also been identified as being particularly useful in providing outcomes to guide the development of health care and health policy (Barbour, 2003). Trustworthiness was promoted by carefully monitoring the research process. The transcripts were read and reread to identify significant comments and emergent themes. Transcripts were read by two researchers (C.J., M.H.), and the themes were further discussed and refined with the research team. Lincoln and Guba (1985) argue that ensuring credibility is one of most important factors in establishing trustworthiness. According to Merriam (1998), the qualitative investigator's equivalent concept: credibility, deals 
with the question, 'How congruent are the findings with reality?'. To check for congruence, the emergent themes were discussed with the advisory group, which includes practitioners involved in the service delivery and young mothers who have previously used the service.

\section{Findings}

The data describe teenage mothers' experiences of sexual health and contraceptive decision making through the use of a home-based nurse-led sexual health service. The data were initially arranged under four headings, 'the rationale for using P2P', 'the experience of the P2P service', 'the contextual factors associated with the use of P2P', and 'the impact of the P2P service' and were then developed into the three substantive themes that account for teenage mothers' experiences of the $\mathrm{P} 2 \mathrm{P}$ service, teenage mothers' reflections of the attitudes of the $\mathrm{P} 2 \mathrm{P}$ nurses, and impact and understanding. These themes are presented below using the teenage mothers' narratives and the authors' interpretations. Sub-themes are also provided in italics.

\section{Teenage mothers' experiences of the P2P service}

Data pertaining to the experiences of the service were arranged into the following sub-themes based on what appeared to be most noteworthy and most valuable in terms of teenage mothers' experiences of the service: 'privacy', 'convenience', 'flexibility' and 'ease and speed'.

\section{Privacy}

For a number of participants, privacy was an issue, and the idea of a home-based service was more preferable. There were many explicit references to the sense of feeling judged, criticised or labelled as a result of being seen in waiting rooms: often these were cited as reasons for appreciating the confidentiality and convenience of home visits from the P2P nurse:

In a clinic I feel intimidated because there's a whole lot of people sitting there and 'Oh, I wonder what they think I'm sat here for? I don't want them to judge you or anything like that. I felt a lot better with them [P2P] coming out to my house.

Well, I think they [GPs] sort of label you all as, yes, like putting it about a bit you know... they forget that people aren't all like that, and you know they're actually bothered and are in like long-lasting relationships.

\section{Convenience}

For a number of other participants, everything about the process of 'appointment making', to accessing contraception through a clinic or GP services, was fraught with 'hassle', problems and inconvenience. Participants talked about not having to 'mess around', 'traipse all over' or 'drag themselves into town' to seek contraception in the early days and weeks after giving birth:

\section{I didn't have to go out and mess about just after giving birth.}

It's good that they can come to your house after you've had a new one so you don't have to lug everything about straight after you've had a baby...

Not surprisingly, this was particularly important for those participants who had surgery. A number of participants reflected on the importance of $\mathrm{P} 2 \mathrm{P}$ in relation to their physical condition after caesarean section:

I were in too much pain to like be going you know far distance to a place where they do it. It's up in town and if you do it down here you've got wait a couple of months I think to get in.

$(\mathrm{K} 30 \mathrm{~N})$

\section{Flexibility}

The fact that participants were seen in their own home was a great asset as was the opportunity to set the date and time of the visit to fit in with their lives - many of which involved sole childcare 
duties and also very recently discharged after caesarean section:

I said can I have a home visit because she is feeding on demand and I'm breast feeding at the moment, so she says we will make a time that is best for you.

I was shocked that she actually came to me, as I wouldn't have got it done if I had to leave the house, I couldn't really move or anything. So I was happy when she came to me.

S20N

The value of the home visit for promoting sexual health was also evident. Some participants identifying that they may have indulged in risk taking behaviour without the $\mathrm{P} 2 \mathrm{P}$ visit:

So when she came out, it was really good because otherwise I wouldn't have been able to get contraception cover so quickly. I would have been going in to town like four weeks after or something. And if I wanted to have sex within that time, it wouldn't have been any good.

(G40N)

\section{Ease and speed}

The participants interviewed described that they were busy following the birth and that contraception may not have been considered or actioned if the P2P nurse had not visited:

Yes they (the P2P nurse) asked what methods I'd like and talked me through them she told me more about the implant and then just there and then had it done. If she had booked an appointment I would have talked myself out of it because I don't do needles.

(B6N)

Me and my partner were talking about it we had not quite decided on what I wanted ... never got round to it, so it was nice for someone to just be there.

Participants experiences of the staff delivering the $\mathrm{P} 2 \mathrm{P}$ service.
Overall participants valued the service and had a positive experience. The experiences were influenced by the nature of the service - and the attitudes and skills of the visiting nurse and the fact that the service provided an opportunity for ongoing support and 'mentorship' should young mothers require this. From the data, there were two sub-themes that represent teenage mothers' reflections of the attitudes and skills of the $\mathrm{P} 2 \mathrm{P}$ nurses: facilitative attitudes and ongoing support.

\section{Facilitative attitudes}

In addition to the flexibility of the home visit, participant's also valued the approach and attitudes of the P2P nurses. This was linked to them feeling they had time and a facilitated choice:

She let me choose the contraception what I wanted and not saying, 'Why don't you have this?' 'Why don't you have that?' she was better.

(C13N)

She talked me through the implant and stuff, but after reading through all the information about them both, I decided that I wanted the injection, because it suited me better than having the implant.

$(\mathrm{N} 22 \mathrm{~N})$

But there was also a sense from participants that previous experiences of gaining contraceptive advice was less than positive and the $\mathrm{P} 2 \mathrm{P}$ service differed in that respect:

It was like more, more listening to them than doctors.

(S31N)

They never really explained it to me [referring to her GP] but the lady who came here, she explained everything to me and then she gave me the injection yes, so it is a lot better, yes and she left me a little booklet as well with all the information in.

$(4 \mathrm{G} 33 \mathrm{~N})$

\section{Ongoing support}

It was clear from the data that the participants valued the potential for ongoing contact with the P2P nurse. Although not a formal part of the service, 
this aspect was seen as important for helping with problems and contraceptive compliance issues:

She showed me what was available, what was best for me, after taking blood pressure and everything like that, and then I decided I wanted the patch. That's what we spoke about after, but then it wasn't good for me anyway, so I had to ring her up and she came back for me. Then she helped me choose something else.

(C13N)

If you have any problems whatsoever you need to come back to me and we'll try and sort something else out for you. But with the patches I've had no problems whatsoever.

(Y21O)

But she still messaged me as well after she'd put it in, she were still texting me to like you know remind me and that which were really good because I've got a very bad memory.

$(\mathrm{K} 30 \mathrm{~N})$

It appeared from the data that the combination of the home environment and the potential for ongoing support created a sort of mentorship and support relationship:

I like the fact that she is available to talk to because if I have any of the questions or problems about anything, she's always there to talk to. And I do ... even if it's just silly questions about saying not to do my injection: I like to talk to [nurse's name]. I feel comfortable like explaining my problems and stuff and then she's always there when I need her to be.

You've got someone to turn to when you need to know something and they are always there for you to contact as well which is good.

( 120$)$

And they kind of kept in touch to make sure everything's alright, and kind of make sure everything's going to plan and fixing things that haven't been, and all that sort of thing. It's been nice.

\section{Impact and understanding}

The positive impact of the service upon the lives of these teenage girls is resounding. Aspects of their lives, which have been most positively affected relate to taking control, developing understanding beyond contraception and preventing repeat pregnancy.

\section{Taking control}

The experience of sexual health and contraceptive decision making in the home, facilitated a greater understanding of contraceptive choices, one which superseded previous experiences of sexual health education at school: 'I distinctly remember having one lesson in year ten and that was it' (M7N), and provided them with more time and greater opportunity to think pragmatically about which contraception(s) would best suit with their current lifestyle with their commitments. Young mothers sometimes expressed what could be identified as a 'diminishing' of their own power (with respect to accessing contraception through the more traditional routes of clinics and GP surgeries). This feeling was related to different factors, however, identifying what they needed from sexual health services, and being able to do this in an environment that they had control of (ie, their own home) appeared to be an empowering factor for these women. The home environment, a setting within which the young mothers felt in control, self-governed and comfortable, stood in contrast to a clinic environment with its imposing constraints in relation to appointment making and waiting times:

I felt comfortable 'cos I didn't want to go there.

(M34N)

It's just more comfortable, you feel like you can talk to her.

(K30N)

With this increased autonomy and decision making about sexual health, came a renewed sense of responsibility for other aspects of their lives:

It's hard. I didn't realise how hard it'd be having him, and then after having him, I realised that I do need to start taking control.

$(\mathrm{N} 22 \mathrm{~N})$ 
If I've got a baby to look after... if I get that implant I can't forget, because if I'm doing things with her and try to do 'house and stuff I might forget, whereas before I didn't have anything to stop me forgetting.

$(\mathrm{C} 36 \mathrm{~N})$

Overall, there was a sense of young women feeling more in control and more able to make decisions about their sexual health and reproductive choices as a result of the knowledge that was imparted during the visit:

I think I'm smarter with it. I mean the talk with the lady that comes to your house, she's clued me up a bit, helped me with the right one and to keep up with it.

\section{Developing understanding beyond contraception}

Understanding of sexual health beyond that of contraception was evident within the data. Young mothers highlighted how their understanding of sexually transmitted infections (STIs) has also improved:

She made me realise that even though you're on...your contraception to stop you from catching on pregnant that you should also use other contraception such as condoms and stuff to prevent you from like sexually transmitted diseases and stuff like that.

Longer term impact was evident: a number of teenage girls indicated that they may have had to either take 'emergency contraceptive measures' if the nurse had not made contact and visited at that time:

There was just no plan, we would have used condoms though.

\section{Preventing repeat pregnancy}

For some young women, the timing of the visit had a significant impact upon their reproductive choices, due to the fact that through time, admittedly they may have forgotten about, or they were too exhausted to identify the need for contraceptive cover:

Yeah, it was the right time because obviously if I had left it any longer my memory would have made me forget because my memory's just appalling.

$(\mathrm{M} 7 \mathrm{~N})$

It were just, I were knackered, never got round to it so it were nice for someone to just be there.

(S8O)

For other young mothers, the potential for a second pregnancy was evident, and the $\mathrm{P} 2 \mathrm{P}$ service was instrumental in preventing this:

I think I would have put it off a lot more. I think I would have just thought, 'I'll ring the doctor today, I'll ring the doctor', and I ring the doctor .... and it'll just get put off and put off and put off and put off ... therefore I probably would have got pregnant again.

$(\mathrm{P} 16 \mathrm{~N})$

So you think 'oh, I'll do it tomorrow' and then tomorrow comes and you think 'oh, I can't be bothered'. So yeah, I think yeah, if she didn't come out then I probably would still be (inaudible - 18:23) I'd probably be on my second child, yeah, I think, yeah.

(E15O)

Well, to be honest, if I didn't have her come out and do it then I probably would have waited until I actually went into town to get him registered and that's ... and you get twelve weeks for that or something. So most likely within that I probably would be pregnant again (laughter).

$(\mathrm{K} 27 \mathrm{O})$

\section{Discussion}

Overall the data reflects that teenager's engagement with home-based contraception is motivated by a need for privacy, convenience, flexibility and appropriately timed access. Within the reflective accounts of accessing contraception prior to $\mathrm{P} 2 \mathrm{P}$, there were many explicit references to the sense of 
feeling judged, criticised or labelled, and it is apparent that aspects such as previous experiences of being seen and judged by others in waiting rooms impacted upon previous decision making in the context of sexual health. The Teenage Pregnancy Strategy: beyond 2010 (DoH, 2010) identifies a clear remit for professionals to convey positive and welcoming messages to young people regarding sexual health, to allay the fear of being judged. Reflected in this data is that a real or perceived lack of privacy, feelings of being judged by others, alongside the inconvenience of $\mathrm{GP} /$ clinic-based access to contraception led many of teenage mothers to be reluctant to engage with vital aspects of sexual health and well-being. Young people need to be able to access sexual health services in environments that are confidential and young people-centred' (DoH, 2010), and this data not only lucidly highlights that $\mathrm{P} 2 \mathrm{P}$ offers this model of, and approach to, sexual and reproductive healthcare, it clearly indicates that teenage mothers appreciate the confidentiality, convenience and privacy of home visits by a nurse.

\section{The psychological impact of home-based care on young mothers}

The approach in which contraceptive counselling is provided has an impact on women's contraceptive decisions (Gemzell-Danielsson et al., 2011). Addressing sexual health needs in the home environment appears to have been key to the effectiveness of the P2P service. The young mothers in the study regularly referred to the home-based service as more 'comfortable' for them; it may be that their perceived comfort was more about the neutrality of the environment, and the role of the P2P nurses as a facilitator to the decision making. When discussing models of empowerment within health promotion strategies, Tengland (2012) refers to 'enabling dialogical conditions' (Tengland 2012: 143), as part of an empowerment approach to health promotion, highlighting the significance of this strategy with respect to individuals changing and moving in a positive direction. Data suggest that not only did the home environment offer a sense of comfort, but that the 'space', facilitated discussions in such a way that the young mothers felt they could ask questions without being embarrassed or overheard by others or feeling intimidated and judged. The appropriate dialogical conditions in turn facilitated a feeling of greater equality between themselves and the practitioner. It may be that the home setting provided more intimacy, greater time, a sense of genuine participation on the part of the $\mathrm{P} 2 \mathrm{P}$ nurses, which led to the young mothers being listened to, and understood with respect to their sexual health needs. In keeping with an empowerment approach to health promotion, the young women in this study did not appear to feel persuaded or coerced into engaging in sexual health decision making, nor were they given instructions about contraceptive use and sexual health, alternatively, they were given choices, through which they became active participants in their reproductive and sexual health decision making, which according to Tengland (2012) can facilitate a sense of gaining control and becoming empowered.

The perinatal period is known to be a time when women are most receptive to health messages (Ruggiero et al., 2000; Anderson, 2001; Wilkinson and McIntyre, 2012). In addition, late adolescence is a time associated with setting the stage for continued development through life. For many adolescents, this stage is associated with making choices and engaging in activities that are influential on the rest of their lives (Zarrett and Eccles, 2006). The young mothers in this study were at a point in life where their choices were not only setting the scene for themselves, but also for their children. The timing of the P2P encounter (late adolescence), and its significance in terms of facilitating a sense of autonomy and active participation in decision making, is not only ideal, but also crucial with respect to the young mother's long-term contraceptive choices. The women in this study, may have been more open to taking on sexual health advice from P2P nurses because of the perceived impact their healthier lifestyles may have on their children, but this receptiveness was also an example of their own age-related movement toward greater independence in decision making (Spano, 2004).

The P2P service appears to provide a flexible approach to service delivery for teenagers, which in turn facilitates a positive engagement with contraceptive use. Data suggest that teenage mothers now use sexual health services around them with less hesitation. This is especially noticeable for those teenage girls who required further advice and support from P2P. The 
awareness of the existence of flexible services creates a feeling of safety and security, and the facilitative attitude of the P2P nurses makes them appear highly accessible. The nurses provide ongoing support: a mentorship-type model of support, ensuring that their clients' chosen method of contraception is, and continues to be suitable for them, and that they are motivated and supported to use it effectively and consistently. Black et al. (2006) previously demonstrated that home-based interventions founded on a mentorship model and targeted towards adolescent development were effective in preventing second births within two years of the adolescent mother's first delivery. This study extends this finding beyond that of preventing unintended second births to illustrating a promising association between teenage mothers taking personal control of their own contraceptive decision making with the right type of support, and becoming more empowered, and this sense of renewed empowerment may in turn encourage confidence in their children with respect to positive relationships and good sexual health. The DoH (2010) identify that all the evidence points to parents being the key influencers of their children's attitudes and behaviours, so positive messages from parents about the importance of safe sex, passed on through the $\mathrm{P} 2 \mathrm{P}$ service, will help to ensure that the children of these teenage mothers use contraception when they become sexually active.

As with first conceptions, subsequent conceptions can be accidental, and providing intensive support can help young women to decide and implement a contraceptive plan in advance of, and following maternity (Hallgarten and Misaljevich, 2007). Conversely, the data presented here illustrate the positive impact of a brief and non-intensive intervention after birth on reproductive health. Not only does the data reflect a clear move from the potential for repeat pregnancy to appropriate contraceptive cover, it also reflects a move towards greater confidence and decision making alongside increased awareness of pertinent sexual health issues.

The findings of this study illustrate what home-based contraceptive services can achieve. The P2P service facilitates improved knowledge around contraception and the ability to apply that knowledge to decision making around wider sexual health matters. What is important is that the lack of confidence in existing contraceptive services, and associated inconsistency in contraceptive use, appears inherently linked to a perceived lack of privacy, choice, time and interest from existing GP-based services, which potentially underpins reluctance to fully engage, or indeed to re-engage with these services when young women encounter a problem with their existing contraception.

This finding around inconsistent, and at times, incorrect use of contraception is accordant with the findings from a number of key reports of teenage conception rates (Hallgarten and Misaljevich, 2007; NICE, 2007; Marie Stopes International, 2009; DoH, 2010). However, our data suggest that existing clinic/GP-based contraceptive services may also leave some young mothers avoiding exploring possible routes to solving contraception problems, as the perception that there is a lack of support renders further exploration seemingly pointless. The teenage mothers in this study discovered that the home-based contraceptive service could offer more than they had previously experienced, that is, support and advice for a period of time that extended beyond the postnatal period, and knowing this has led to them having confidence to be more actively involved in decision making. This is of particular relevance when there is a continued political emphasis on sexual and reproductive health services to provide one to one advice on prevention and screening for STIs, prevention of unintended pregnancies, all methods of reversible contraception, and access and use of emergency contraception, alongside other reproductive issues and concerns (NICE, 2007).

\section{Conclusion}

The data from this study demonstrate that the service has been effective in preventing repeat pregnancies in a number of cases within this group of teenage mothers. The provision of a brief intervention in the postnatal period, facilitates longer term plans with respect to sexual and reproductive health. Consequently, a significant community of young people can be empowered to improve their own knowledge and understanding, and engage more effectively. This is a positive way of communicating sexual health information to young people.

Primary Health Care Research \& Development 2016; 17: 287-297 
Finally, across England there is considerable regional variation in how sexual health services are provided and commissioned (DoH, 2014), and localities have varying degrees and models of service provision for teenage mothers. Within health service provision, resource distribution is reportedly challenging, however, in order to ensure appropriate and effective implementation of the guidance on prevention of STIs and under-18 conceptions (NICE, 2007), commissioners and service providers should consider how services can be better tailored to meet the needs of teenage mothers who have recently given birth.

\section{Implications for clinical practice}

Heath professionals, practitioners and commissioners may underestimate the considerable stigma of accessing sexual health care via GP practices and clinic-based services for teenage mothers and indeed for young people in general.

Teenage mothers report struggling to access sexual health services after giving birth and consideration needs to be given to how best to support this group of young people with respect to their sexual health needs.

The United Kingdom still has the highest rate of teenage pregnancies in Western Europe (NICE, 2007), and qualitative accounts of teenager mothers highlight that home-based contraceptive care can prevent unplanned pregnancy after childbirth and promote good sexual health.

Teenager mothers who engage with home-based contraceptive services have increased perceptions of support, greater clarification about sexual health service provision, and increased knowledge, confidence and empowerment.

The combination of increased knowledge along with an understanding of referral processes and support services, empowers teenage mothers to approach sexual health decision making in a more proactive way.

\section{Limitations}

Although a representative and relevant sample of teenage mothers were identified, and the sample size was appropriate, recruitment was at the lower end of the anticipated numbers. This was mainly due to difficulties engaging teenage mothers at a

Primary Health Care Research \& Development 2016; 17: 287-297 time when there are considerable demands placed on them with respect to the first weeks and months after childbirth. In addition, the sensitivities associated with the subject matter and its implications for reproductive and sexual health may have contributed to teenage girls' reluctance to engage in the process. Alternatively, sexual and reproductive health is a highly personal subject that teenagers may not have wished to explore.

\section{Acknowledgements}

This research was supported by the National Institute for Heath Research. The authors gratefully acknowledge the contributions of Rotherham, Doncaster and South Humber NHS Sexual Health Services, and the participating families who made the research possible.

\section{Financial Support}

This article presents independent research funded by the National Institute for Health Research (NIHR) under its Research for Patient Benefit (RfPB) Programme (Grant Reference Number PB-PG-0711-25014). The views expressed are those of the author(s) and not necessarily those of the NHS, the NIHR or the Department of Health.

\section{References}

Anderson, S. 2001: Pregnancy as a time for dietary change? Symposium on nutritional adaptation to pregnancy and lactation. Retrieved 5 June 2015 from http://journals.cambridge.org/ download.php?file=\%2FPNS\%2FPNS60_04\%2FS0029665101 000581a.pdf $\&$ code $=17 f 7 b 4597512$ d6bb6dc05fe2f918880a

Arai, L. 2009: What a difference a decade makes: rethinking teenage pregnancy. Social Policy and Society 8, 171-83.

Barbour, R.S. 2003: The newfound credibility of qualitative research? Tales of technical essentialism and co-option. Qualitative Health Research 13, 1019-27.

Birch, D.M.L. 1997: The adolescent parent - a fifteen year longitudinal study of school-age mothers and their children. Journal of Adolescent Health and Welfare 10, 17-25.

Black, M.M., Bentley, M.E., Papas, M.A., Oberlander, S., O'Teti, L., McNary, S. and O'Connell, M. 2006: Delaying second births among adolescent mothers: a randomized controlled trial of home based mentoring programme. Paediatrics 118, 1087-99.

Collier, J. 2009: The rising proportion of repeat teenage pregnancies in young women presenting for termination of pregnancy from 1991 to 2007. Contraception 79, 393-96. 
Corbin, T. 2004: Mortality in children aged under 8. Health Statistics Quarterly 24, 35.

Department of Health (DoH). 2014: Commissioning regional and local HIV sexual and reproductive health services: guidance. Retrieved 5 November 2014 from https://www.gov.uk/ commissioning-regional-and-local-sexual-health-services

Department of Health (DoH). 2010: Teenage pregnancy strategy: beyond 2010. Retrieved 6 November 2014 from https:/www.education.gov.uk/consultations/downloadableDocs/ 4287_Teenage\%20pregnancy\%20strategy_aw8.pdf

Furstenberg, F.F., Brooks-Gunn, J. and Morgan, S.P. 1987. Adolescent mothers and their children in later life. New York: Cambridge University Press.

Gale, N.K., Health, G., Cameron, E., Rashid, S. and Redwood, S. 2013: Using the framework for analysis of qualitative data in multi-disciplinary health research. BMC Medical research methodology. Retrieved 5 June 2015 from; http://www. biomedcentral.com/1471-2288/13/117

Gemzell-Danielsson, K., Thunell, L., Lindenberg, M., Tyden, T., Marintcheva-Petrova and Oddens, B.J. 2011: Comprehensive counselling about combined hormonal contraceptives changes the choice of contraceptive methods: results of the CHOICE program in Sweden. Acta Obstetricia et Gynecologica Scandinavica $90,868-77$.

Hallgarten, L. and Misaljevich, N. 2007: Reducing repeat teenage conceptions: a review of practice: Commissioned by the Teenage Pregnancy Partnership in Hackney and the City. Retrieved 9 November 2014 from http://www.efc.org.uk/PDFs/ reducing-repeat-teenage-conceptions-review-of-practice.pdf

Klerman, L.V. 2004: Another chance: preventing additional births to teen mothers. Retrieved 3 November 2014 from http://www.healthyteennetwork.org/sites/default/files/ anotherchance_final.pdf

Lincoln, Y.S. and Guba, E.G. 1985. Naturalistic enquiry. California: Sage Publications.

Marie Stopes International. 2009: "The condom broke" Why do women in the United Kingdom (UK) have unintended pregnancies? Research and analysis 3. Retrieved 9 November 2014 from http://mariestopes.org/data-research/ resources/condom-broke-why-do-women-uk-have-unintendedpregnancies

Meade, S.C. and Ickovics, J.R. 2005: Systematic review of sexual risk among pregnant and mothering teens in the USA: pregnancy as an opportunity for integrated prevention of STD and repeat pregnancy. Social Science and Medicine 60, 661-78.

Merriam, S.B. 1998: Qualitative research and case study applications in education, San Francisco: Jossey-Bass.

Murtagh, J., Dixey, R. and Rudolf, M. 2006: A qualitative investigation into the levers and barriers to weight loss in children: opinions of obese children. Archives of Disease in Children 91, 920-23.

Nanchahal, K., Wellings, K., Barrett, G., Copas, A., Mercer, C., MacManus, S., MacDowall, W., Fenton, K., Erens, B. and Johnson, A. 2005: Changes of circumstances of young mothers in Britain: 1990 to 2000. Journal of Epidemiology and Community Health 59, 828-33.

National Institute for Health and Clinical Excellence. 2007: Prevention of sexually transmitted infections and under 18 conceptions. Retrieved 5 November 2014 from http://www. nice.org.uk/guidance/ph3/resources/guidance-prevention-ofsexually-transmitted-infections-and-under-18-conceptions-pdf

Office for National Statistics. 2015: Statistical bulletin: conceptions in England and Wales 2013. Office for National Statistics, February 2013. Retrieved 28 June 2015 from http://www.ons.gov.uk/ons/dcp171778_396674.pdf

Owen, J., Carroll, C., Cooke, J., Formby, E., Hayter, M., Hirst, A. and Sutton, A. 2010: School-linked sexual health services for young people (SSHYP): a survey and systematic review concerning current models, effectiveness, cost-effectiveness and research opportunities. Retrieved 20 November 2014 from http://www.ncbi.nlm.nih.gov/pubmedhealth/PMH00149 78/pdf/summ1430.pdf

Rigsby, D., Macones, G. and Driscoll, D. 1998: Risk factors for rapid repeat pregnancy among adolescent mothers: a review of the literature. Journal of Paediatric and Adolescent Gynaecology 11, 115-26.

Ritchie, J. and Spencer, L. 1994: Qualitative data analysis for applied policy research. In Bryman, A. and Burgess G., editors Analysing qualitative data. London: Routledge, 173-85.

Rowlands, S. 2010: Social predictors of repeat adolescent pregnancy and focussed strategies. Best Practice and Research Clinical Obstetrics and Gynaecology 24, 605-16.

Ruggiero, L., Tsoh, J.Y., Everett, K., Fava, J. and Guise, B.J. 2000: The transtheoretical model of smoking: Comparison of pregnant and non-pregnant smokers. Addictive Behaviour 25, 239-51.

Spano, S. 2004: Stages of adolescent development. Retrieved 12 June 2015 from http://www.actforyouth.net/resources/rf/ rf_stages_0504.pdf

Teenage Pregnancy Independent Advisory Group. 2009: Teenage pregnancy independent advisory group annual report 2008/ 2009. Retrieved 9 November 2014 from http://dera.ioe.ac.uk/ 14266/1/The_Independent_Advisory_Group_on_Teenage_ Pregnancy_Sixth_annual_report_20082009\%5B1\%5D.pdf

Tengland, P. 2012: Behaviour change or empowerment: on the ethics of health promotion strategies. Public Health Ethics 5, 140-53.

Wellings, K. 2007: Causes and consequences of teenage pregnancy. In Baker, P., Guthrie, K., Hutchinson, C., Kane, R. and Wellings, K., editors Teenage pregnancy and reproductive health. London: RCOG Press, 69-80.

Wilkinson, S.A. and McIntyre, H.D. 2012: Evaluation of the healthy start to pregnancy early antenatal health promotion workshop: a randomised controlled. BMC Pregnancy and Childbirth 12, 1-12.

Zarrett, N. and Eccles, J. 2006: The passage to adulthood: challenges of late adolescence. Retrieved 14 June 2015 from http://onlinelibrary.wiley.com/doi/ 10.1002/yd.179/epdf 